\title{
Measuring Plant Stress with an Infrared Thermometer
}

\author{
J.L. Hatfield \\ National Soil Tilth Laboratory USDA-ARS, Ames, LA 50011
}

Infrared thermometers are rapid, reliable instruments for measuring foliage temperature. These instruments are relatively simple to use with only a few considerations, e.g., field of view, target dimensions, and calibration. The foliage temperature can be incorporated into crop water stress indices that have been related to soil water availability and leaf water potential. The number of samples that need to be collected is relatively small. The infrared thermometer provides a technique for the remote detection of stress in all types of plants.

Plant stress measurements with the hand-held infrared thermometer (IRT) have become increasingly popular in the last 10 years following the introduction of the portable, battery-powered IRT. Digital displays of foliage temperature allowed for quick and easy measurements. Possible sources of error and potential uses of the IRT to measure water stress will be presented. It is assumed that the reduction of soil water will result in stomata] closure and cause an increase in foliage temperature. In practice, any situation (e.g., disease, fertility, root pruning) that affects transpiration will affect foliage temperature.

\section{Theory of operation}

Infrared thermometers measure the energy emitted by the surface focused onto the detector instead of surface temperature as such. A complete theoretical treatment of infrared sensors and filters is given by Wolfe and Zissis (1978). The IRT detector is filtered to allow only a specific waveband, typically 8 to $14 \mathrm{~km}$, onto the detector. A 10.5 - to $12.5-\mu \mathrm{m}$ waveband is commonly used to avoid strong water absorption bands. This captured energy, E, is converted to temperature $(\mathrm{T})$ via Stefan's Law, which states $\mathrm{E}=\varepsilon \sigma \mathrm{T}^{4}$, where $\varepsilon$ is the emissivity of the object and $\sigma$ the Stefan-Boltzman constant $\left(5.68 \times 10^{-8}\right.$ Joules $\mathrm{m}^{-2} \cdot \mathrm{s}^{-1} \cdot$ Kelvin $\left.^{-4}\right)$. Energy emitted is proportional to the fourth power of temperature and the emissivity of the surface. Emissivity can be thought of as an "emittance efficiency factor"; most biological objects vary from 0.9 to 0.99 for the 10.5- to $12.5-\mu \mathrm{m}$ waveband. Not correcting for emissivity can cause a 1 to $3 \mathrm{~K}$ error. Most plants have emissivities of 0.97 to 0.99 in this waveband; however, a correction may be necessary if a particular method requires a high accuracy of temperature measurement. Measurements of emissivity can be made using the method described by Fuchs and Tanner (1966) and Idso et al. (1969).

The amount of energy gathered into the detector depends on the field of view (FOV) of the instrument; however, energy flux is normalized to a unit area. The FOV is considered as the angle of the apex of a cone with the apex being the detector. A large FOV will "see" more area while a narrow FOV will "see" only a small spot. Infrared thermometer FOVs range from 0.1 to $50^{\circ}$; however, most IRTs used in plant stress research have a 4 or $15^{\circ} \mathrm{FOV}$. The larger the FOV, the more area will be represented by the average temperature. With a small FOV, one can measure a spot temperature. A $1^{\circ}$ FOV may be used to measure fruit or flower temperature that requires a defined target to be seen.

It is important to understand that the distance the IRT is held from the object does not influence the surface temperature recorded, but does affect the size of the viewed area (Fig. 1). The viewed area of a $4^{\circ}$ FOV IRT held perpendicular to the target will increase as a function of the distance. O'Toole and Real (1984) discuss this problem in their description of IRT target size. The energy emitted by a surface and detected by the IRT is not influenced by the intervening atmosphere because it is nearly transparent to the sensitive wavebands of the IRT.

\section{Calibration}

Like any other instrument, the IRT requires calibration to provide accurate and reliable readings. Several manufacturers of IRTs sell blackbody standards that can be used as a device to check the stability of an IRT, however, these are not calibration devices. A recommended procedure to check the stability of an IRT is to compare the IRT reading with the blackbody standard before and after a series of field measurements. If there is a stability problem with the IRT, or if it is sensitive to ambient conditions, this comparison will detect these errors.

Calibrations of the IRT are best made in controlled situations where the ambient temperature can be maintained relatively constant and the target temperature varied from 0 to 50C. Calibration standards range from blackbody cones positioned in controlled waler baths to specifically designed units for IRT calibration (Wolfe and Zissis, 1978). A blackbody standard can be constructed from a thin, metal cylinder, preferably copper, with a slanted sealed end. The interior should be painted with a dull, flat black paint. and calibrated high resolution temperature sensors should be attached to the outside surface where the IRT detects the temperature. This configuration increases the area viewed by the IRT. Commercially available calibration standards use either parallel or concentric v-shaped grooves or intersecting conical cavities to increase the surface area of the plate. These plates are thermoelectrically controlled and typically control the temperature to within 0.5C (Wolfe and Zissis, 1978). Calibration is done by comparing the IRT temperature reading to the temperature of the calibration standard. All IRTs should be calibrated once per year and checked daily, when in use, against a portable secondary standard to evaluate stability. Sadler and van Bavel (1982) describe a simple procedure for calibrating an IRT that would be appropriate for most researchers.

\section{Principles of use}

Primary precautions that should be taken when using an IRT are the FOV and the angle at which the IRT is positioned relative to the object (O'Toole and Real, 1984). A wide FOV IRT, e.g., 15', will view a large target area and could possibly detect energy emitted by the soil, surrounding plant, or sky. These objects may be at temperatures different from the intended target and create a source of error that depends on the magnitude of the temperature difference between the intended target and other objects and the relative area of the FOV they occupy. All of these extraneous energy sources influence the temperature displayed on the IRT. O'Toole and Real (1983) discussed the implications of FOV on the proper use of the

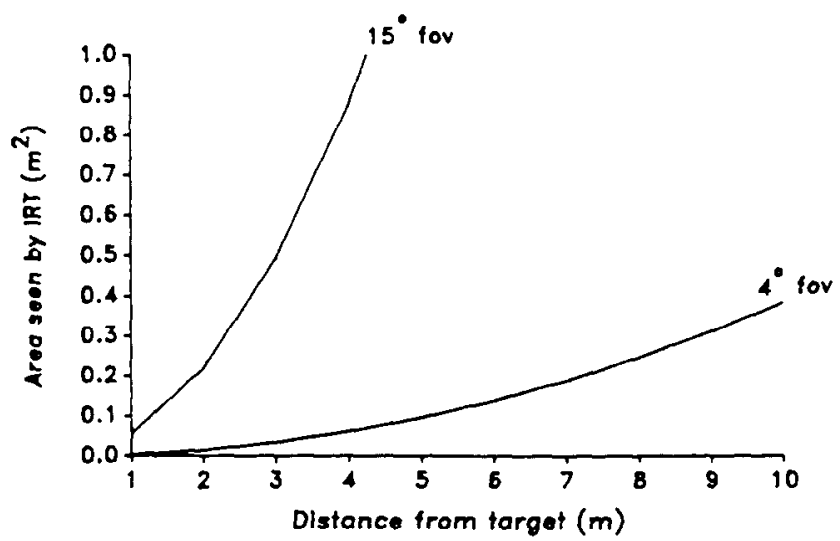

Fig. 1. Influence of IRT distance from the target on the area seen by the IRT when it is positioned perpendicular to the target, for two fields of view (FOV). 
IRT. They showed that a large FOV IRT, e.g., $15^{\circ}$, would be affected by the sky temperature when the IRT was held at an angle close to horizontal.

A temperature response limitation exists with the IRT in that the detector does not respond immediately to changes in surface temperature. The time constant of most IRTs is $0.5 \mathrm{sec}$; however, it is possible to sample more quickly than the IRT's time constant with portable data collection systems. Thus, the recorded temperature may not be the true temperature, but a measure of changing temperature as the IRT approaches a new surface. Moving the IRT from one leaf to another and electronically recording the data at a fast sample interval, e.g., 0.1 sec., may cause unknown errors in the data. This problem can easily be avoided by reducing the sampling speed or allowing the IRT to attain an equilibrium temperature.

Another source of error that is often overlooked is the modification of the surface temperature caused by shading the surface with the IRT. The IRT is often held close to the object to view small areas. This practice may shade the surface and reduce the temperature of sunlit leaves, fruits, ore flowers. Shading the leaf with and IRT for an extended period of time, 20 to 30 sec., can cause significant changes in the surface temperature.

\section{Plant stress measurements}

The utility of plant stress measurements with an IRT comes from the ease of use and the incorporation of physical principles into the interpretation of the measurement. Surface temperature measurements can be used in closely related energy balance or enzyme kinetic methodologies.

Plant stress in the energy balance method can be quantified by one of two methods: an empirical approach developed by Idso et al. (1981), or a theoretical approach developed by Jackson et al. (1981). A comparison between foliage and air temperature $\left(T_{f}-\right.$ $\mathrm{T}_{\mathrm{a}}$ ) provides the basis for the methodology in both of these calculations. In the Idso method, the temperature difference is combined with the vapor pressure deficit (VPD) to compare the $T_{f}-T_{a}$ of a potentially well-watered crop with the actual $T_{f}-T_{a}$. The lower baseline represents the maximum rate of transpiration of a wellwatered crop and it has been shown that $T_{f}-T_{a}$ decreases as the VPD increases. The upper baseline represents the $T_{f}-T_{a}$ of a canopy with no transpiration and the temperature difference does not respond to VPD (Fig. 2). Any measured value of $T_{f}-T_{a}$ should theoretically fall between these two boundaries. The resultant index varies from 0 to 1 with 1 being a plant having no transpiration loss and 0 representing a plant transpiring at the maximum rate. The crop water stress index with the Idso method is shown diagrammatically in Fig. 2. To calculate the crop water stress index (CWSI), the comparison is made between the expected and actual lower $T_{f}-T_{a}$ values relative to an upper baseline as:

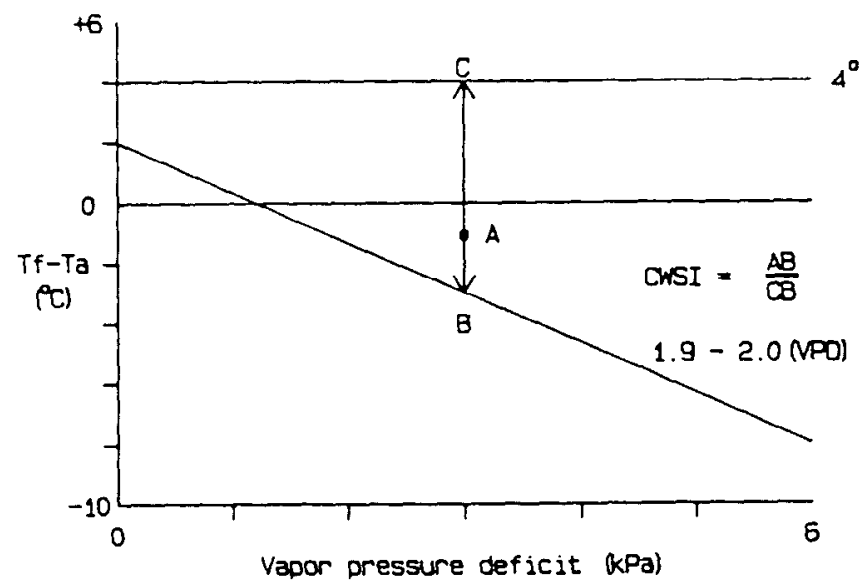

Fig. 2. Crop water stress index calculation based on the Idso method of relating $\left(T_{f}-T_{a}\right)$ and water vapor pressure deficit.

$$
\begin{gathered}
\text { CWSI }=\left[\left(T_{f}-T_{3}\right)-\left(T_{f}-T_{f}\right)_{1}\right] / \\
{\left[\left(T_{f}-T_{2}\right)_{4}-\left(T_{f}-T_{2}\right)_{1}\right]}
\end{gathered}
$$

where $\left(T_{f}-T_{a}\right)_{1}$ represents the lower baseline and $\left(T_{f}-T_{a}\right)$, the upper baseline (Eq. [1]). The lower baseline is determined from' observations of $T_{f}-T_{a}$ for a well-watered crop throughout a day to obtain a range in VPD. A linear regression line is fit through the data to obtain the baseline. Howell et al. (1984a) showed that the lower baseline did not exhibit any seasonal change. The upper baseline is determined by the method of Idso et al. (1981).

One of the primary limitations in the Idso method occurs in humid regions with low VPD. At low VPD, differences between the foliage and air temperature are small and thus near the accuracy limit of the IRT. The latter is simply not sensitive to changes in water stress at these high humidities. Other limitations in the Idso-CWSI method are possible changes in the lower-baseline throughout the growing season (Wanjura et al., 1990) and the influence of wind on the upper baseline (O'Toole and Hatfield, 1983).

The Jackson method that uses a complete energy balance equation also calculates a stress index that ranges from 0 (no stress) to 1 (complete stress). This method requires a measurement of net radiation, VPD, and an estimate of the aerodynamic resistance and foliage resistance under unlimited water supply. The methodology for calculating the CWSI with the Jackson method is given by:

$$
\begin{aligned}
\text { CWSI }= & E_{a} / E_{p}=\left[\left(1+r_{d} / r_{a}\right)-\gamma^{*}\right] / \\
& {\left[\Delta+\gamma\left(1+r_{d} / r_{a}\right)\right] }
\end{aligned}
$$

where $E_{a}$ is the actual evaporation, $E_{p}$ the potential evaporation, $g$ the psychrometric constant $(\mathrm{Pa} / \mathrm{C}), \mathrm{r}_{\mathrm{c}}$ the canopy resistance $\left(\mathrm{s} \cdot \mathrm{m}^{-1}\right)$, $r_{a}$ the aerodynamic resistance $\left(s \cdot \mathrm{m}^{-1}\right), \gamma \bullet$ the potential psychrometric constant, and $\Delta$ the slope of saturation vapor pressure curve $(\mathrm{Pa} / \mathrm{C})$. The ratio of $r_{c}: r_{a}$ is expressed as:

$$
\begin{gathered}
r_{d} r_{2}=\left[\gamma r_{2} R_{\sigma} /\left(\rho C_{p}\right)-\left(T_{1}-T_{2}\right)(\gamma+\Delta)-\right. \\
\left.\left(e^{*}-c_{2}\right)\right] /\left\{\gamma\left[\left(T_{f}-T_{3}\right)-r_{2} R_{n} /\left(\rho C_{p}\right)\right]\right\}
\end{gathered}
$$

where $R_{n}$ is net radiation $\left(\mathrm{J} \cdot \mathrm{m}^{-2} \cdot \mathrm{s}^{-1}\right)$, $\mathrm{p}$ air density $\left(\mathrm{kg} \cdot \mathrm{m}^{-3}\right), \mathrm{C}_{\mathrm{p}}$ heat capacity of air $\left(\mathrm{J}^{\mathrm{kg}} \mathrm{kg}^{-1}\right.$ per degree Celsius $), \mathrm{e}_{\mathrm{a}}{ }^{*}$ saturation vapor pressure at $\mathrm{T}_{\mathrm{a}}(\mathrm{Pa})$, and $\mathrm{e}_{\mathrm{a}}$ actual vapor pressure of the air $(\mathrm{Pa})$.

This approach provides a fairly sensitive method of calculating a CWSI, but aerodynamic and foliage resistance values are difficult to define. In practice, the aerodynamic and foliage resistance terms are assumed to be a constant for a crop. However, both resistances should be calculated to determine the correct value for a given day. If the resistances are assumed constant, then differences between actual and assumed values can cause CWSI values to be $<0$ or $>$ 1.0. Hatfield (1985) described a methodology for obtaining foliage resistance values. Aerodynamic resistance needs to be evaluated for the particular surface because the stress index is sensitive to these changes. Hatfield et al. (1985) described some of the limitations in calculating aerodynamic resistance, such as the degree of ground cover and temperature gradients in the atmosphere.

Both the Idso and Jackson estimates of plant stress have been correlated to yield (Smith et al., 1985; Walker and Hatfield, 1983), soil salinity (Howell et al., 1984b), leaf water potential (O'Toole

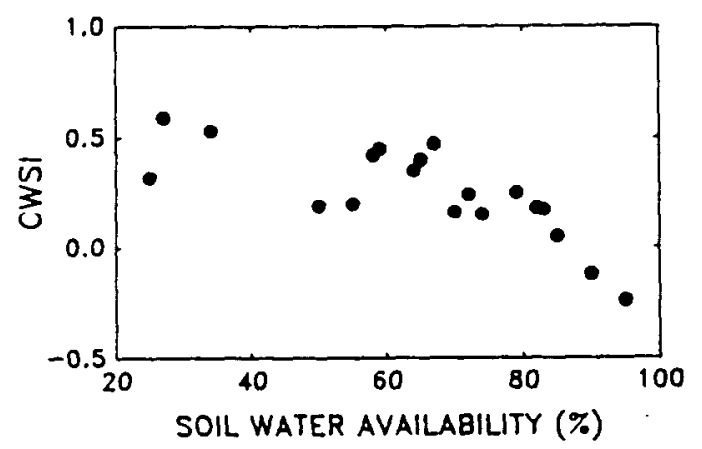

Fig. 3. Change in crop water stress index from the Jackson method as a function of the available soil water in the upper $1.5 \mathrm{~m}$ of a wheat canopy (Hatfield et al., 1987). 


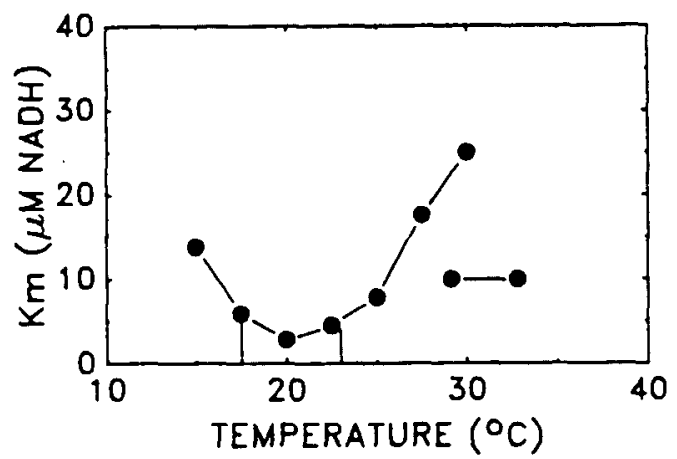

Fig. 4. Temperature response curve of glyoxylate reductase for NDAPH in the region within $200 \%$ of the minimum $\mathrm{Km}$ depicted by the vertical lines. (Halfield et al., 1987).

et al., 1984, Pinter and Reginato, 1981), and soil water availability (Hatfield, 1983; Reginato and Garrett, 1987). These correlations have been carried out for various crops with similar relationships found between the stress index and the individual parameter. Figure 3 shows an example of the Jackson method for computing crop water stress index and its relationship to soil water availability in wheat. Turner (1981) showed that the time requirement for collecting surface temperature data was less than other methods of measuring plant stress.

Recently, foliage temperatures have been related to the temperature response of the enzymes within the plant. Burke and Hatfield (1987) showed that it was necessary to consider the foliage temperature-enzyme activity relationship to fully quantify the protection level of glutathione reductase in field-grown wheat. Mahan et al. (1990) found a unique thermal optimum of the enzymes glutathione reductase for NADPH and glyoxylate reductase for NADH for various species and defined the thermal kinetic window for these enzymes as the foliage temperatures that provided apparent $\mathrm{Mi}$ chaelis constant, $\mathrm{Km}$, values within $200 \%$ of the minimum $\mathrm{Km}$ (Fig. 4). The minimum apparent $\mathrm{Km}$ can be considered to be a representation of the efficiency of the reaction process, with the lower $\mathrm{Km}$ representing the faster rate of reaction. The minimum apparent $\mathrm{Km}$ occurs at the optimum foliage temperature; however, the width of the window in terms of foliage temperature has nor been fully defined nor investigated. Hatfield et al. (1987) found that foliage temperatures were nearly equal to air temperature at night and began to separate from the latter at temperatures that provided for optimum enzyme function. This separation was within the range of 23 to $32 \mathrm{C}$ for cotton, 10 to $17 \mathrm{C}$ for spinach, and 30 to $40 \mathrm{C}$ for cucumber. However, the capability of the plant to maintain these foliage temperatures for optimum enzyme function was dependent on soil water availability, net radiation, and air temperatures (Mahan and Upchurch, 1988; Upchurch and Mahan, 1988). The findings of Mahan and Upchurch (1988) and Upchurch and Mahan (1988) revealed that cotton plants would maintain temperatures at $28 \pm 2 \mathrm{C}$. A stress on the plant occurs when the foliage temperature is outside of this range under conditions of high net radiation (> $500 \mathrm{~J} \cdot \mathrm{m}^{-2} \cdot \mathrm{s}^{-1}$ ), air temperature $>28 \mathrm{C}$, and soil water availability near field capacity. These results indicate that coupling of temperalure response of enzymes with the foliage temperature provides an additional quantification of plant stress.

\section{Sampling procedures}

Hatfield et al. (1984b) found that foliage temperature measurements in irrigated fields could be collected in a random manner and that a sample size of 10 would be adequate to characterize the field mean. They found that the field variability of surface temperature increased as soil water decreased. Thus, the surface temperature increased as soil water decreased and the number of samples taken had to increase in order to maintain a constant standard error. The number of samples should be set at the beginning of an experiment and maintained throughout a treatment cycle. This practice requires a prior knowledge of the level of differences the experimenter wishes to detect.

The presence of reproductive structures, e.g.. flowers or fruits, presents a unique sampling problem. These structures, which are typically nontranspiring, if exposed to full sunlight, can be as much as 3 to $5 \mathrm{C}$ warmer than transpiring leaves. If the plant material has reproductive structures in the instrument FOV, then the sampling procedure may need to be modified from an oblique to a more nadir (vertical) angle to avoid seeing these warmer structures. The implications of this problem on the calculation of a crop water stress index have been discussed by Hatfield et al. (1984a).

\section{CONCLUSIONS}

Use of the IRT provides a rapid, accurate procedure for collecting foliage temperature data for use in assessing plant stress within certain limitations. Foliage temperature used in conjunction with other meteorological data allows a quantitative assessment of plant stress. The utility lies in the ability to rapidly collect data to provide an accurate time course of stress development. Crop water stress indices have not been fully developed for horticultural crops, but several researchers are beginning to apply these techniques. As with all techniques, there are limitations in using the IRT. These are primarily in the area of sampling and developing crop stress relationships for crops with limited ground cover and small leaves because of the interference of soil background. There are still refinements to be made in the technique that will benefit plant science.

\section{Literature Cited}

Burke, J.J. and J.L. Hatfield. 1987. Plant morphological and biochemical responses to field wate deficits. III. Effect of foliage temperature on the potential activity of glutathione reductase. Plant Physiol. 85:100-103.

Fuchs, M. and C.B. Tanner. 1966. Infrared thermometry of vegetation. Agron. J. 58:597-601.

Hatfield, J.L. 1983. The utilization of thermal infrared radiation measurements from grain sorghum as a method of assessing their irrigation requirements. Irr. Sci. 3:259-268.

Hatfield, J.L. 1985. Wheat canopy resistance determined by energy balance techniques. Agron. J. 77:279-283.

Hatfield, J.L., P.J. Pinter, J.., E. Chasseray, E. Ezra, R.J. Reginato, S.B. Idso, and R.D. Jackson. 1984a. Effects of panicles on infrared thermometer measurements of canopy temperature in wheat. Agr. Met. 32:97105.

Hatfield, J.L., M. Vauclin. S.R. Vieria, and R. Bernard. 1984b. Surface Temperature variability patterns within irrigated fields. Agr. Water Mgmt. 8:429-437.

Hatfield, J.L., D.F. Wanjura, and G.L. Barker. 1985. Canopy temperature response to water stress under partial canopy. Trans. Amer. Soc. Agr. Enc. 28:1607-1611.

Hatfield, J.L., J.J. Burke. J.R. Mahan, and D.F. Wanjura. 1987. Foliage temperature measurements: A link between the biological and physical environments. Int. Conf. on Measurement of Soil and Plant Water Status. vol. 2, Utah State Univ., Logan, p. 99-102.

Howell, T.A., J.L. Hatfield. H. Yamada, and K.R. Davis. 1984a. Evaluation of cotton canopy temperaturc to detect crop water stress. Trans. Amer. Soc. Agr. Eng. 27:84-88.

Howell, T.A., J.L. Hatfield, J.D. Rhoades, and M. Meron. 1984b. Response of cotton waler s!rcss indicators to soil salinity. Irr. Sci. 5:25-36.

Idso. S.B., R.D. Jackson. W.L. Ehrlcr, and S.T. Mitchell. 1969. A method for determination of infrared emittance of leaves. Ecology 50:899-902.

Idso, S.B., R.D. Jackson, P.J. Pinter, Jr.. R.J. Reginaro, and J.L. Hatfield. 1981. Naturalizing the stress-degree-day parameter for environmental variability. Agr. Met. 24:5-55.

Jackson, R.D., S.B. Idso. R.J. Reginaro, and P.J. Pinter, Jr. 1981. Canopy tcmperature as a crop water stress index. Water Resources Res. 17:11331138 .

Mahan, J.R. and D.R. Upchurch. 1988. Maintenance of constant leaf temperature by plants. I. Hypothesis limited homeothcrmy. Env. Expt. Bot. 28:351-357.

Mahan, J.R., J.J. Burke, and K.A. Orzech. 1990. Thermal dependence of the apparent $\mathrm{Km}$ of glutathionc reductases from three plant species. Plant Physiol. 93:822-824.

O'Toolc. J.C. and J.L. Hatfield. 1983. Effect of wind on the crop wafer stress index derived by infrared thermometry. Agron. J. 75:811-817.

O'Toolc, J.C. and J. Real. 1984. Canopy target dimensions for infrared thermometry. Agron. J. 76:863-865.

O’Toole, J.C., N.C. Turner. O.P. Namuco, M. Dingkukn, and K.A. Gomez. 
1984. Comparison of some crop water stress measurement methods. Crop Sci. 24:1121-1128.

Pinter, P.J., Jr., and R.J. Reginato. 1981. Thermal infrared techniques for assessing plant water stress. Proc. Amer. Soc. Agr. Eng. In. Sch. Conf., Amer. Soc. Agric. Eng., St. Joseph, Mich. p. 1-9.

Reginato, R.J. and D.J. Ganet, Jr. 1987. Irrigation scheduling with the crop water stress index. Western Cotton Production Conf. Summary Proceedings. p. 7-10.

Sadler, E.J., and C.H.M. van Bavel. 1982. A simple method to calibrate an infrared thermometer. Agron. J. 74:1096-1098.

Smith, R.G.C., H.D. Barrs, J.L. Steiner, and M. Stapper. 1985. Relationship between wheat yield and foliage temperature: Theory and its appli- cation to infrared measurements. Agr. For. Met. 36:129-143.

Turner. N.C. 1981. Techniques and experimental approaches for the measurement of plant water stress. Plant and Soil 58:339-366.

Upchurch, D.R. and J.R. Mahan. 1988. Maintenance of constant leaf temperature by plants. Il. Experimental observations in cotton. Env. Expt. Bat. 28:359-366

Walker, G.K. and J.L. Hatfield. 1983. Stress measurement using foliage temperature. Agron. J.. 75:623-629.

Wanjura, D.F., J.L. Hatfield, and D.R. Upchurch. 1990. Crop water stress index relationships with crop productivity. In. Sci. 11:93-99.

Wolfe, W.L. and G.J. Zissis (ed). 1978. The infrared handbook. Office of Naval Research. Dept. of the Navy. Arlington, Va. 